\title{
$\mathrm{PH} 102$ accuaitiad
}

\section{Europeana y GIF IT UP fomentan la creatividad en tiempos de pandemia}

Europeana, plataforma digital europea para el patrimonio cultural, sostiene que defender el patrimonio cultural puede ser muy divertido y ha organizado una nueva edición de GIF IT UP, una competición anual basada en la creación de gifs (graphics interchange format, en sus siglas en inglés) para fomentar la reutilización de material de patrimonio cultural de una forma creativa. Cada año, durante el mes de octubre, tanto animadores profesionales como entusiastas del patrimonio cultural, están invitados a crear innovadores gifs mezclando material sin derechos y de licencia abierta procedente de bibliotecas digitales de varias partes del mundo.

Aleksandra Strzelichowska | Europeana Foundation (Traducción del inglés original: Berta Corredor)

URL de la contribución <http://www.iaph.es/revistaph/index.php/revistaph/article/view/4830>

Esta competición fue creada en 2013 y está organizada por Europeana, en estrecha colaboración con la Digital Public Library of America, la neozelandesa Digital NZ y la Biblioteca Nacional de Australia Trove. En 2020 dos nuevos socios se han unido a la iniciativa: Japan Search y los Museos DAG en Calcuta, India. El Art Institute of Chicago ya ha solicitado unirse para este año 2021.

Europeana es una plataforma digital europea para el patrimonio cultural y sus instituciones que tiene como propósito su empoderamiento para que puedan llegar a

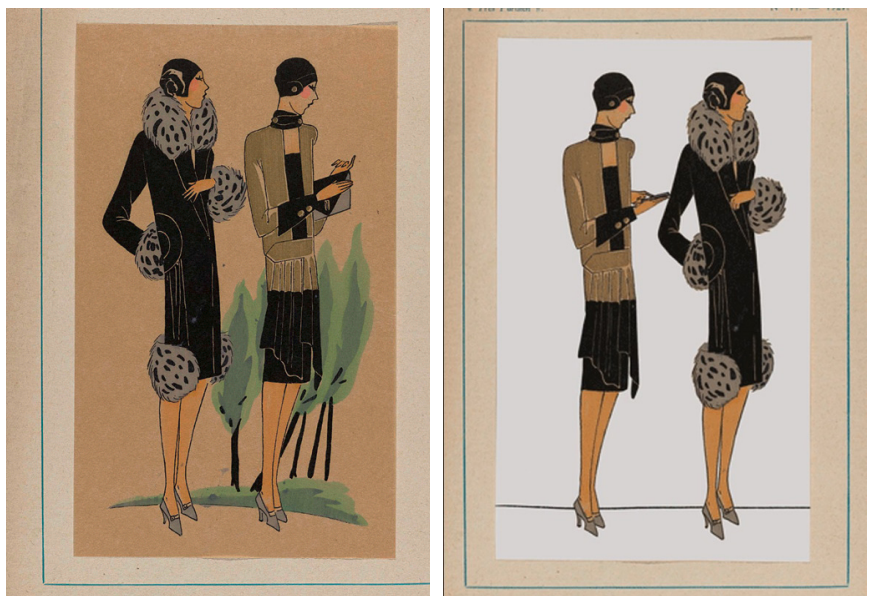

Gif ganador de edición 2020. Autora: Nisha Alberti (Edinburgh, Escocia). Fuente original: Très Parisien (Rijksmuseum via Europeana) compartir sus colecciones con el mundo. A través de la página de colecciones de Europeana, millones de objetos de patrimonio cultural, alrededor de 4.000 instituciones de toda Europa, están disponibles. Europeana trabaja para compartir y promover esta herencia para que gente de todo el mundo pueda tanto utilizarla como disfrutarla. Su trabajo contribuye a formar una sociedad más abierta, creativa y culta. La Fundación Europeana es la organización a la que la Comisión Europea ha encomendado la función de desarrollar una plataforma cultural digital para Europa. Europeana está co-financiada por la Connecting Europe Facility de la Unión Europea.

\section{GIF. El lenguaje de Internet}

¿Sabían que los gifs son el segundo formato de imagen más popular en Internet después del jpeg? A pesar de que ha estado con nosotros más de 30 años, no se hicieron populares hasta aproximadamente el año 2010 con el auge de las redes sociales, en especial Tumblr. Incluso el Oxford Dictionary consideró gift como "palabra del año" en 2012.

Fáciles de usar, los gifs están por todas partes. Se utilizan para expresar reacciones, ilustrar de una forma rápida y fácil y para mostrar importantes momentos de la cultura pop. Pero incluso pueden llegar a convertirse en una forma de arte. Las limitaciones del formato, una paleta de 256 colores, así como su pequeño tamaño, 

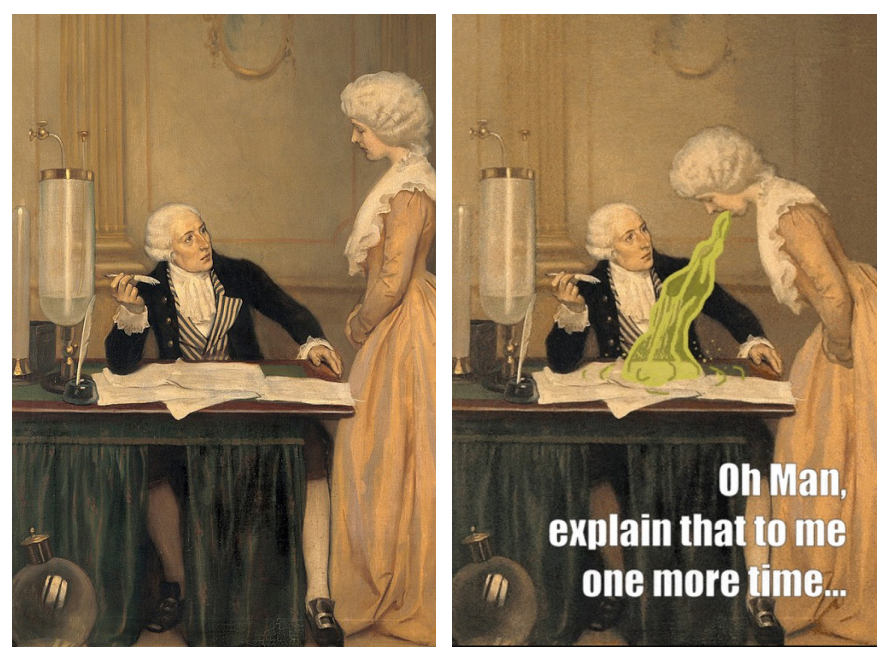

Gif finalista en la edición 2020 del concurso. Autora: Helene Nozon (Rostock, Alemania). Fuente original: Lavoisier explaining to his wife the result of his experiments on air. Oil painting by Ernest Board

suponen un interesante desafío a los artistas que tienen que contar su historia en tan sólo unos segundos.

\section{Un patrimonio cultural digital que pueda utilizar y ver todo el mundo}

Crear un gif es rápido y simple y hay multitud de herramientas y aplicaciones que hacen posible diseñar uno con tan solo unos clicks. Pero, a pesar de que la cantidad de patrimonio cultural online es inmensa, mucha gente no sabe aún que puede usarse libremente para proyectos de todo tipo: educativos, creativos, de investigación, incluso simplemente por diversión. Otro obstáculo es el desconocimiento general que existe sobre el permiso de su uso, lo que supone que muchos simplemente no los utilicen si piensan que no están autorizados para ello.

GIF IT UP supone una solución para esto, ya que educa al usuario de una forma práctica y entretenida. Todo el contenido de patrimonio usado en el concurso contiene información clara sobre su autorización. Los participantes están invitados a echar un vistazo a las colecciones que ya han sido seleccionadas para encontrar inspiración. La utilización correcta del material es un desafío. Cada año, muchas aplicaciones son rechazadas por un uso incorrecto de este. Sin embargo, cada participante que envía una solicitud no admisible recibe un correo con una explicación clara y es invitado a buscar el permiso necesario de la institución que posee el material, o bien, presentar otro gif. Esa es nuestra manera de educar al público participante y reconocer su esfuerzo. Y en general recibimos una respuesta positiva, incluso de aquellos que tienen que comenzar su animación desde el principio.

\section{Creativitividad en tiempos de pandemia}

En 2020 hemos pasado más tiempo trabajando online que antes. Internet es donde trabajamos, jugamos e interactuamos con los otros. Con muchos museos y galerías cerrados durante gran parte del año, la exploración del patrimonio cultural en línea se generalizó más que nunca. En tiempos difíciles, la gente se volcó hacia el arte para encontrar una perspectiva histórica, una forma tranquila de pasar el tiempo en el encierro, o simplemente como entretenimiento. $Y$ con esta variedad de clases, eventos, cursos y talleres en línea, podían aprender nuevas habilidades. Todo esto hizo de GIF IT UP una actividad perfecta para 2020. Con los recursos y tutoriales disponibles en los sitios web del concurso, todos los que quisieran participar podían crear algo y enviar su creación. Fue genial ver cómo los participantes se ayudaban entre sí escribiendo publicaciones de blog e incluso creando un curso de Skillshare sobre creación de gifs. Las presentaciones en 2020 realmente expresaron lo que la gente estaba sintiendo este año, con animaciones que mostraban distanciamiento social, usar máscaras y quedarse en casa. Y la categoría de fondo GIPHY introducida en 2020 hizo posible utilizar las creaciones como fondo en reuniones en línea.

\section{El arte como parte de la vida diaria}

El concurso dura un mes, pero la vida útil de las presentaciones de GIF IT UP es mucho más larga. Se agregan al canal GIPHY del concurso, donde aparecen en los resultados de búsqueda entre gifs de TV, música y cultura pop y reciben millones de visitas durante todo el año. A través de teclados GIF y complementos, pueden compartirse tanto en otras plataformas de redes sociales como en diversas aplicaciones.

¿Todavía dudas en participar? Desde Europeana te invitamos a que lo hagas. Crea tu propio gif y nos vemos en GIF IT UP 2021! Puedes consultar los ganadores de la edición 2020 en: https://gifitup.net 